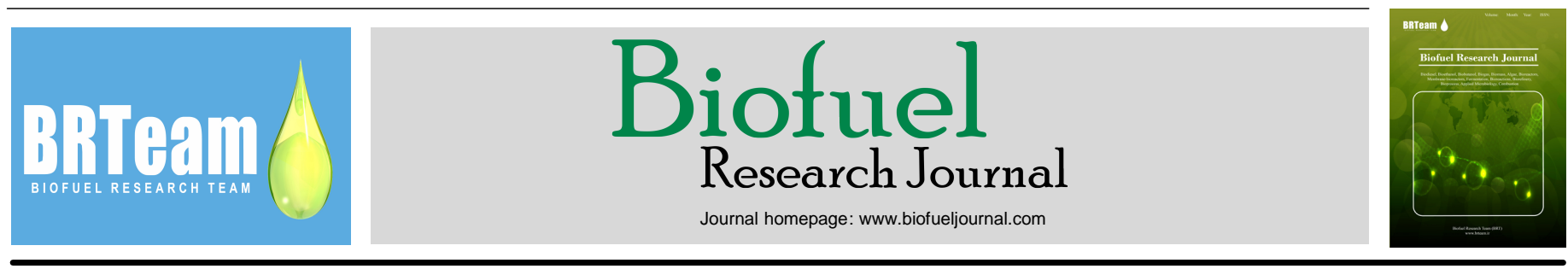

Original Research Paper

\title{
The in-process removal of sterol glycosides by ultrafiltration in biodiesel production
}

André Y. Tremblay*, Alessandro Montpetit

Department of Chemical and Biological Engineering, University of Ottawa, Ottawa, ON, Canada K1N 6N5.

\section{HIGHLIGHTS}

$>$ The presence of sterol glycosides in biodiesel limits its widespread use.

$>$ Removed sterol glycosides from soybean oil at biodiesel process conditions.

$>$ Related separation factor to $\mathrm{pH}$ and methanol

content of reaction mixture.

$>$ In process separation technology reduces need for

post processing of biodiesel

\section{GRAPHICAL ABSTRACT}

\section{Permeated FAME (SG reduction by $86 \%$ )}

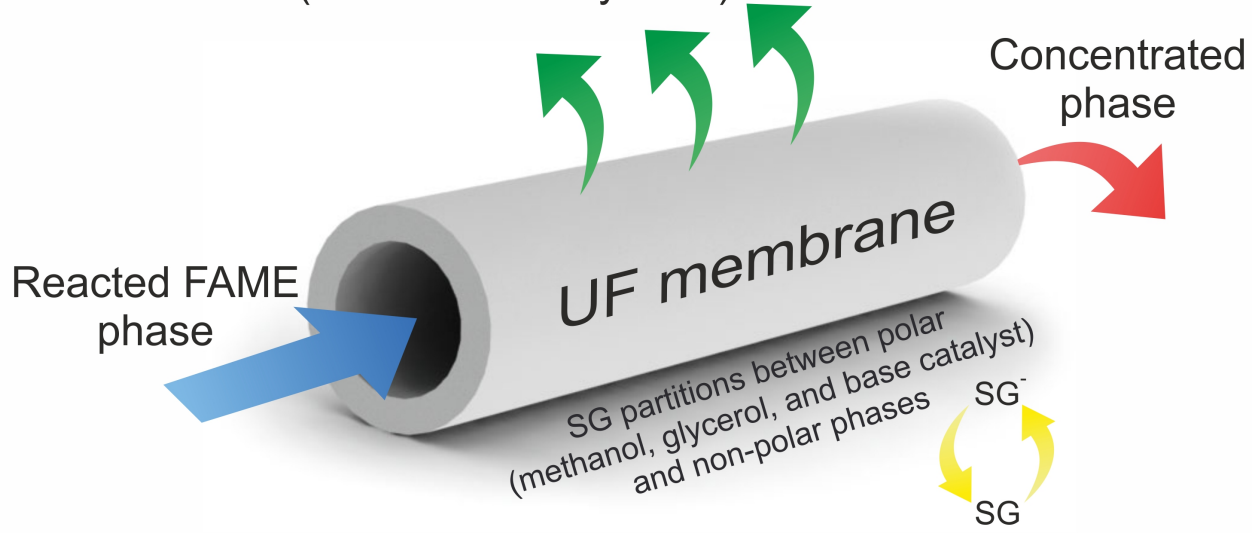

\section{ARTICLE INFO}

\section{Article history:}

Received 15 December 2016

Received in revised form 5 February 2017

Accepted 5 February 2017

Available online 1 March 2017

\section{Keywords:}

Sterol glycoside

Biodiesel

FAME

Purification

Ultrafiltration

\begin{abstract}
Minor components found in biodiesel can affect its stability and cold flow properties. Without extensive post treatments, trace compounds such as sterol glycosides (SG) can remain at unacceptable levels in finished biodiesel fuels. This study proposes to remove SG from reacted Fatty Acid Methyl Ester (FAME) mixtures using ultrafiltration. Degummed soybean oil was transesterified using methanol and a catalyst (sodium methoxide). The mixtures were immediately ultrafiltered after the react ion and the FAME from the retentate and permeate were analyzed for SG. The highest separation for SG ( $86 \%$ ) was obtained when the reaction conditions were $0.7 \mathrm{wt} . \%$ catalyst and 4:1 MeOH:Oil ratio. The lowest separation (0\%) was observed at 0.3 wt. $\%$ catalyst and 4:1 MeOH:Oil ratio. The higher separations were explained by the deprotonation of the hydroxyl groups on SG. This decreased the solubility of SG in the reacted FAME phase. The separation was lowest, when unreacted oil along with monoacylglyc erides (MG) and diacylglycerides (DG) solubilized SG in the reacted mixture. The separation was also low when high methanol to oil ratios were used in the transesterification. The lowest concentration of SG measured in FAME treated by ultrafiltration was $3.4 \mathrm{ppm}$. The results indicate that ultrafiltration is an effective method to remove SG from soybean FAME.
\end{abstract}




\section{Introduction}

Biodiesel is a renewable alternative to conventional petroleum diesel. It is mostly produced by the transesterification of vegetable oils or animal fats using short chain alcohols in the presence of a catalyst. Poor conversion results in the presence of partially reacted intermediates, such as monoacylglycerides (MG) and diacylglycerides (DG), in the residual fuel. This can affect the cold temperature operability of the fuel. The presence of minor components, such as plant sterols, can also affect the operability and stability of the fuel. Acylated sterol glycosides (ASG) are an important class of natural compounds that are part of plant cell walls and are fully soluble in oil. Although feedstock oil is degummed before being transesterified to biodiesel, these compounds must still be removed in various polishing steps prior to fuel use. During the transesterification process, ASG is converted to sterol glycosides (SG) which are relatively insoluble in biodiesel and will precipitate over time decreasing the fuel's cold weather operability. SG precipitates act as seeds for the crystallization of minor components found in biodiesel such as MG and DG (Gerpen et al., 2011).

Overall, the presence of SG in biodiesel affects its cold flow properties and widespread use. Accordingly, several studies aimed at reducing SG levels in finished biodiesel have been carried out. Enzymatic removal has been shown to reduce SG levels by $81 \%$ with the addition of a synthetic codon-optimized version of the LacS gene expressed from E. Coli (Aguirre et al., 2014). This enzyme is water-soluble, and so, the hydrolysis of SG is mass transfer-limited between the aqueous phase and biodiesel phase. The addition of a surfactant, polyglycerol polyricinoleate (PGPR), was found to increase the hydrolysis rate from $8 \%$ to $81 \%$. The surfactant is partially soluble in biodiesel, which may pose additional problems. However, the enzyme was stable over a large range of $\mathrm{pHs}$ and could be added to the water washing process.

Filtration of $1 \mathrm{~kg}$ of soybean biodiesel at room temperature through $5 \mathrm{~g}$ of diatomaceous earth reduced the SG content from $68 \mathrm{ppm}$ to $20 \mathrm{ppm}$ (Lee et al., 2007). The MG, DG, and triacylglycerides (TG) concentrations did not change as a result of the filtration. The filter blocking test (ASTM D2068) performed on the soy biodiesel before and after filtration showed a substantial reduction in the value of the filter blocking tendency, decreasing from 15.03 (maximum value attainable by ASTM D2068) to 1.01(Lee et al., 2007). The main issue with the filtration of finished biodiesel is the requirement to chill large volumes of biodiesel (Danzer et al., 2015). Finally, distillation has been shown to produce biodiesel esters devoid of any minor components (Gerpen et al., 2004), but like cooling, distillation increases production costs.

The purpose of this work was to study the effect of ultrafiltration on the separation of SG with the aim of removing SG from unwashed biodiesel, also known as fatty acid methyl ester (FAME), without cooling or distillation. The separation was performed on reacted FAME mixtures, at the temperature used in the reaction and in the presence of methanol and catalyst. The viscosity of the feed mixture was reduced under these conditions, which led to an increase in the permeation rate of FAME through the membrane.

\section{Materials and Methods}

\subsection{Reactants}

Degummed soybean oil was used in the production of the FAME studied in this work. The oil was kept in an airtight opaque container and shaken before use. Chloroform $(0.75 \%$ ethanol, ACS grade), methanol (ACS grade), ndodecane $\left(99 \%\right.$, NBP $215^{\circ} \mathrm{C}-217^{\circ} \mathrm{C}$ ), pyridine $(99 \%), \mathrm{HCl}, \mathrm{N}-$ Methyl-N(trimethylsilyl) trifluoroacetamide (silylation grade), and sodium methoxide ( 25 wt.\% in methanol) were purchased from Fisher Scientific Canada.

Monoolein, diolein, triolein, and tricaprin GC standards were purchased from Chromatographic Specialities Inc. Stock solutions and calibration curves for MG, DG, TG, and tricaprin were produced according to ASTM D6584. SG standard was purchased from Matreya Inc. (25mg, Catalogue \#1117).

\subsection{Instrumentation}

GC analysis was used to determine the amount of SG, MG, DG, and TG in the FAME samples produced in this work. SG, MG, and DG present in the FAME samples were silylated with N-methyl-N-(trimethylsilyl) trifluoroacetamide (MSTFA) prior to analysis.
The characterization of MG, DG, and TG was performed according to ASTM D6584. A Restek MTX-Biodiesel column from Chromatographic Specialties (Brockville, ON) with a $2 \mathrm{~m} \times 0.53 \mathrm{~mm}$ ID retention gap and a $15 \mathrm{~m} \times 0.32 \mathrm{~mm}$ ID and a $0.1 \mu \mathrm{m}$ film thickness was used in a gas chromatograph (3800 GC Varian). The GC-FID analysis was based on the test method for the determination of free and total glycerine in B-100 (ASTM D6584). The calibration of the GC system was achieved by the use of an internal standard, tricaprin, and various amounts of SG, MG, DG, and TG as described in ASTM D6584. The operating conditions for the oven were $50^{\circ} \mathrm{C}$ for $1 \mathrm{~min}, 15^{\circ} \mathrm{C} / \mathrm{min}$ to $180^{\circ} \mathrm{C}, 7^{\circ} \mathrm{C} / \mathrm{min}$ to $230^{\circ} \mathrm{C}, 30^{\circ} \mathrm{C} / \mathrm{min}$ to $380^{\circ} \mathrm{C}$, then hold for $10 \mathrm{~min}$. The carrier gas was helium at a constant flow of $3.5 \mathrm{~mL} / \mathrm{min}$, the detector was a flame ionization detector (FID) held at $380^{\circ} \mathrm{C}$, cool on-column injection was used with a sample injection of $1 \mu \mathrm{L}$. All chromatographic data was analyzed using the PeakSimple software (SRI Instruments).

Centrifugation was only used in analyzing SG in FAME using the method described by Montpetit and Tremblay (2016). Temperature controlled centrifugation was carried out using a Hermle Z400K centrifuge, equipped with a Hermle 220.97 rotor $\left(28^{\circ}\right.$ fixed angle, max radius $9.5 \mathrm{~cm}$ and a max speed of $6000 \mathrm{rpm}$, equivalent to $3820 \times \mathrm{g}$ ). The centrifuge was cooled to $-8^{\circ} \mathrm{C}$ for $30 \mathrm{~min}$ prior to use. The final centrifugation was carried out in a variable angle (IEC HN-SII) centrifuge equipped with a horizontal 958 swing-type rotor. A clearly defined pellet was formed at the bottom of the centrifuge tube using the swing-type rotor. The isolation of the fine solids dispersed in n-dodecane was more effective using this type of centrifuge.

\subsection{Production of FAME and ultrafiltration}

A tubular $\mathrm{TiO}_{2}, 300 \mathrm{kDa}$ MWCO, tubular membrane (TAMI Industries) was used to filter the FAME produced from degummed soybean oil. A total of 15 catalyst concentrations and methanol to oil ratios were studied. The catalyst concentration was varied from 0.3 wt. $\%, 0.5$ wt. $\%$, and 0.7 wt. $\%$ sodium methoxide on an oil basis. The methanol ratio was varied from 4:1, 5:1, 6:1, 7:1, and 9:1 methanol:oil on a molar basis. These conditions were selected to represent typical methanol and catalyst levels used in commercial biodiesel production. The reactor consisted of a $500 \mathrm{~mL}$ threeneck flask heated by a hot water bath, a condenser, and thermometer. The FAME were left to react for $60 \mathrm{~min}$, after which the recirculation pump was turned on while keeping the mixture temperature at $60^{\circ} \mathrm{C}$. A transmembrane pressure of $40-50$ psi (276 to $345 \mathrm{kPa}$ ) was applied, and the permeate stream was collected in a graduated cylinder. After $100 \mathrm{~mL}$ were collected, the rest of the reacted FAME mixture was transferred to a separatory funnel placed in a $50^{\circ} \mathrm{C}$ hot water bath and allowed to de-phase for $60 \mathrm{~min}$. The glycerol was separated from the retentate FAME phase by gravity settling. Both FAME streams were neutralized using concentrated $\mathrm{HCl}$. After neutralization, the methanol in both FAME samples was removed in a rotary evaporator at $350 \mathrm{mbar}, 60^{\circ} \mathrm{C}$ for $3 \mathrm{~h}$.

\subsection{Isolation and analysis of SG in FAME samples}

SG was decompatibilized from the methanol evaporated FAME according to the method developed by Montpetit and Tremblay (2016), and the isolated precipitates were analyzed by GC-FID using the method outlined in ASTM D6584. The SG concentration in each sample was determined by measuring the area within the range of relative retention times (RRT) of 1.21-1.3. The RRT was based on the internal standard tricaprin (Montpetit and Tremblay, 2016).

\section{Results and Discussion}

\subsection{Calibration curve}

In order to determine the concentration of SG in the FAME samples; a calibration curve was produced using a commercial SG standard purchased from Matreya LLC. (25 mg steryl glycosides, cat \#1117). A standard solution containing $5 \mathrm{mg}$ of $\mathrm{SG}$ in $1 \mathrm{~mL}$ of chloroform/methanol $(2: 1)$ solvent was prepared. Specific volumes of this standard solution $(100 \mu \mathrm{L}$, $70 \mu \mathrm{L}, 40 \mu \mathrm{L}, 20 \mu \mathrm{L}$, and $10 \mu \mathrm{L}$ ) were pipetted in a glass vial and dried using a light stream of nitrogen gas. After drying, $100 \mu \mathrm{L}$ of the tricaprin 
standard was added and the solids were silylated with $100 \mu \mathrm{L}$ of MSTFA. The solution was left to react for $45 \mathrm{~min}$ and then diluted with $4 \mathrm{~mL}$ of anhydrous heptane. This solution was analyzed by GC-FID using a $1 \mu \mathrm{L}$ injection volume. The tricaprin was detected at $21.5 \mathrm{~min}$ and SG at $26-28 \mathrm{~min}$. The area from the relative retention time of 1.21 to 1.3 was measured using multiple peak integration and divided by the area of the tricaprin internal standard. The calibration curve used in this work was generated as described in Montpetit and Tremblay (2016) and had an $\mathrm{R}^{2}$ of 0.9974.

\subsection{Sterol glycoside (SG) separation}

FAME samples from the membrane retentates and permeates produced using the experimental conditions listed in Section 2.3 were analyzed using the method described by Montpetit and Tremblay (2016). The separation factor $(\mathrm{SF})$ for each run was calculated using Equation 1 as follows:

$S F=\left(1-\frac{[S G]_{\text {permeate }}}{[S G]_{\text {retentate }}}\right) \times 100 \%$

The SF for each run was plotted against the MeOH:Oil ratio and is shown in Figure 1 . The SF for low catalyst concentrations $(0.3 \mathrm{wt} . \%$ and $0.5 \mathrm{wt} . \%)$ was seen to increase with increasing MeOH:Oil ratio, until it reached a maximum at 7:1 MeOH:Oil. It then dropped when the MeOH:Oil ratio increased to 9:1. The SF in the FAME produced using $0.7 \mathrm{wt} . \%$ catalyst was highest $(86 \%)$ at 4:1 MeOH:Oil ratio then decreased linearly with a value of $\mathrm{R}^{2}=0.9512$ to a separation of 53\% at a $\mathrm{MeOH}$ :ratio of 9:1.
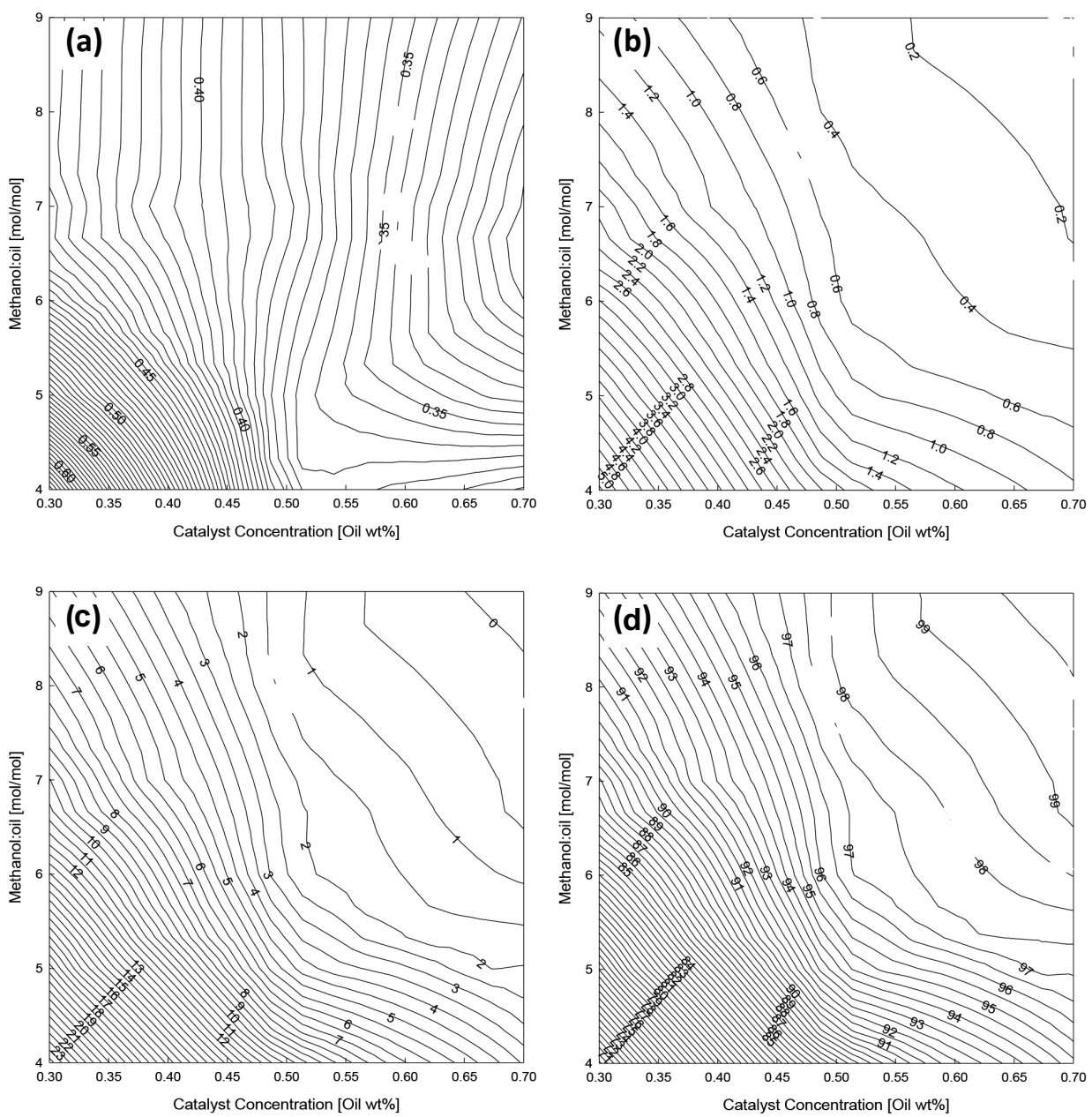

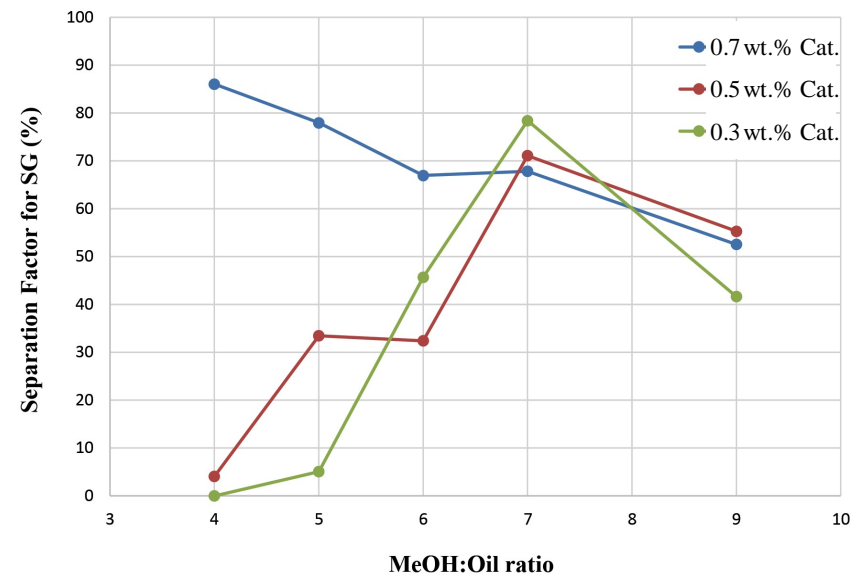

Fig.1. Sterol glycoside separation factor (SF) vs. MeOH:Oil ratio.

\subsection{Characterization of unreacted components}

In order to fully characterize the FAME produced in these experiments; the percent weight of MG, DG, and TG in the samples were determined 
according to ASTM D6584. Samples containing high levels of unreacted TG were further diluted with anhydrous heptane, prior to injection, to decrease the loading in the GC column. The total conversion of saponifiable matter was determined based on the permeate stream. The conversion was calculated by subtracting the fraction of MG, DG, and TG in wt.\% in the permeate stream from 100. Contour plots of MG, DG, TG, and conversion of the FAME permeate were generated using SYSTAT (Systat Software Inc.) and are shown in Figure 2.

At low methanol ratios, MG content was seen to decrease with increasing catalyst concentration. It was relatively constant at higher $\mathrm{MeOH}$ :Oil loadings. The MG content of all the FAME produced was less than $0.8 \mathrm{wt} . \%$, the limit set by EN 14214. The DG content was found to decrease with increasing catalyst concentration and increasing $\mathrm{MeOH}$ :Oil ratio for all methanol loadings. The runs at high MeOH:Oil and high catalyst concentration met the 0.2 wt. \% limit for DG set by EN14214 while others did not. The unreacted TG content in the FAME was seen to decrease with increasing catalyst concentration and increasing $\mathrm{MeOH}$ :Oil ratio. The run at high $\mathrm{MeOH}$ :Oil and high catalyst concentration met the $0.2 \mathrm{wt}$ \% limit for TG set by EN14214.

The conversion of saponifiable material in the oil increases with increasing catalyst concentration and $\mathrm{MeOH}$ :Oil ratio, which was consistent with general observations found in the literature.

\subsection{The effect of $M G, D G$, and $T G$}

Crude soybean oil can contain up to $2300 \mathrm{ppm}$ of SG (Lee et al., 2007). The separation of SG was plotted against TG content (wt.\%) and can be found in Figure 3. The SF was seen to increase sharply, then decreased with increasing levels of TG. The increase in separation was due to a decrease in the methanol present in the FAME phase. The effect of methanol on separation will be discussed in Section 3.6 of this work. The decrease was attributed to the partial solubility of SG in soybean oil. As the TG content in the FAME increased up to 24 wt.\%, the partial solubility of SG in the FAME phase also increased which caused its passage through the membrane. This trend did not appear in the FAME samples produced from $0.7 \mathrm{wt} . \%$ catalyst. These samples were low in TG and other factors dominated in explaining the solubility of SG in FAME under these conditions.

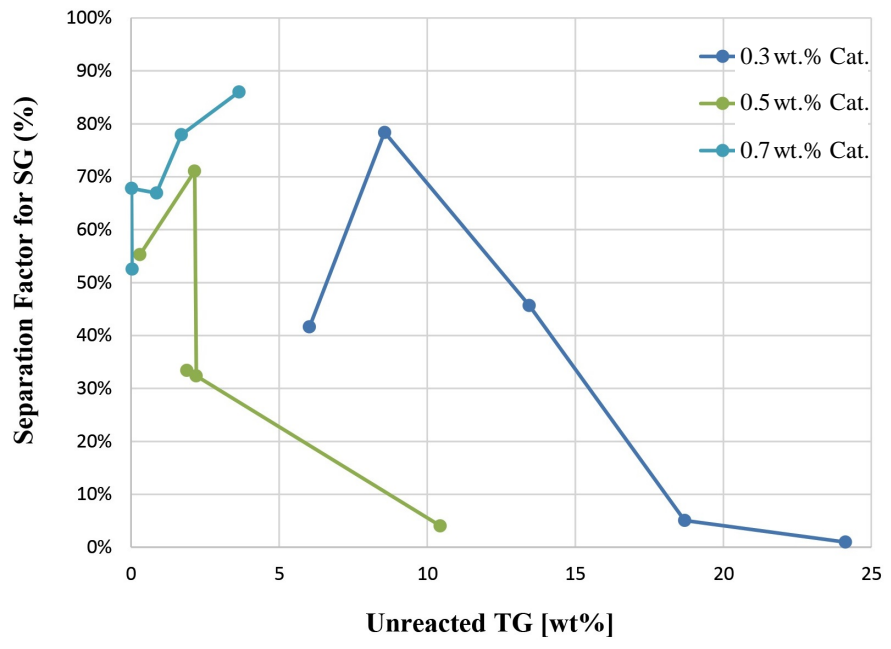

Fig.3. Separation factor for SG vs. unreacted TG [wt.\%] in the permeated FAME.

MG and DG can form hydrogen bonds with the hydroxyl groups on SG and increase its solubility in FAME. The TG content of the permeated samples was plotted against the number of hydroxyl groups (-OH mol\%) in MG and DG calculated using Equation 2, and can be found in Figure 4.

$-\mathbf{O H}(\mathbf{m o l} \%)=\frac{\left[\left(2 \times \frac{\text { Mass }_{\mathrm{MG}}}{\mathrm{MW}_{\mathrm{MG}}}\right)+\frac{\text { Mass }_{\mathrm{DG}}}{\mathrm{MW}_{\mathrm{DG}}}\right]}{\left[\frac{\mathrm{Mass}_{\mathrm{MG}}}{\mathrm{MW}_{\mathrm{MG}}}+\frac{\mathrm{Mass}_{\mathrm{DG}}}{\mathrm{MW}_{\mathrm{DG}}}+\frac{\mathrm{Mass}_{\mathrm{TG}}}{\mathrm{MW}_{\mathrm{TG}}}+\frac{\mathrm{Mass}_{\mathrm{FAME}}}{\mathrm{MW}_{\mathrm{FAME}}}\right]} \times 100$
As seen in Figure 4, the number of hydroxyl groups found in MG and DG was proportional to the amount of unreacted TG in the FAME. This correlation makes it difficult to discern if the passage of SG through the ultrafiltartion membrane was due to the increased solubility of SG in TG or the increased hydrogen bonding with MG and DG. However, the results did indicate that poorly reacted oils would solubilize more SG in the organic phase of the transesterification process. In commercial processes, this will lead to a greater amount of SG in the FAME before it is washed. This will impose higher loads on the final washing and polishing processes used in purifying the FAME before it meets ASTM standards.

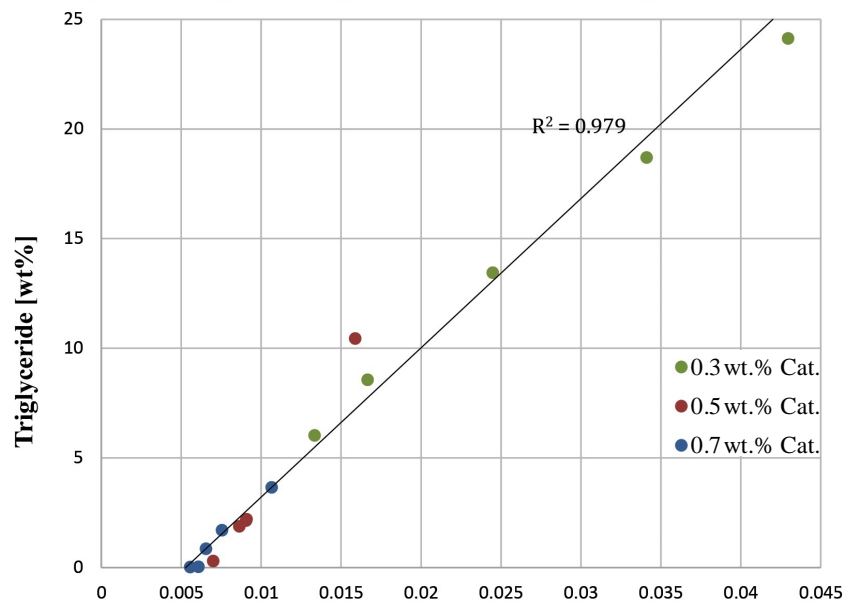

Fraction of hydroxyl groups in MG and DG in the permeated FAME [mol\%]

Fig.4. Unreacted triacylglycerides [wt.\%] vs. fraction of hydroxyl groups in MG and DG [mol\%] in the permeated FAME.

\subsection{Effects of deprotonation}

Sodium methoxide is predominantly found in the polar methanol/glycerol phase during the transesterification process. Unreacted TG is hydrophobic and lowers the methoxide concentration in the FAME phase. The presence of a base catalyst in the reactive mixture will favour the deprotonation of SG and make it less soluble in the organic FAME phase. This will occur as the $\mathrm{pH}$ of the polar phase approaches the pKa of SG. The lower pKa of stigmasterol glucoside is reported as 12.21 (http://www.chemspider.com/Chemical-Structure.5034827.html). To study the effects of deprotonation on the solubility of SG in FAME catalyst phase partitioning data was used to estimate the $\mathrm{pH}$ in the polar phase after the reaction (Csernica and Hsu, 2012). The FAME samples produced in the $0.7 \mathrm{wt} \%$ catalyst runs were selected to study the effects of deprotonation. Under these conditions, the concentration of catalyst in the polar phase and the $\mathrm{pH}$ of the phase is highest for the runs performed at the lowest $\mathrm{MeOH}$ :Oil ratios. Figure $\mathbf{5}$ shows the separation factor for FAME produced using $0.7 \mathrm{wt} \%$ catalyst plotted against the estimated $\mathrm{pH}$ of the polar phase. Increasing the $\mathrm{pH}$ of the polar phase causes increased deprotonation of the hydroxyls on the SG. This increases their solubility in the polar phase and decreases their solubility in the FAME phase. This is observed in Figure 5 where an increase in the $\mathrm{pH}$ of the polar phase causes an increase in SG separation.

\subsection{Effects of excess methanol on solubility}

The value of the Hildebrand solubility parameter of a solvent mixture can be determined from the values of the Hildebrand solubility parameters for individual solvents in a mixture on a volume basis. The solvent system of acetone/methanol $(9: 1 \mathrm{v} / \mathrm{v})$ can be considered a good solvent for SG as it is used to elute SG in column chromatography. This solvent mixture has a total Hildebrand solubility value of $20.90 \mathrm{MPa}^{0.5}$. A system of 


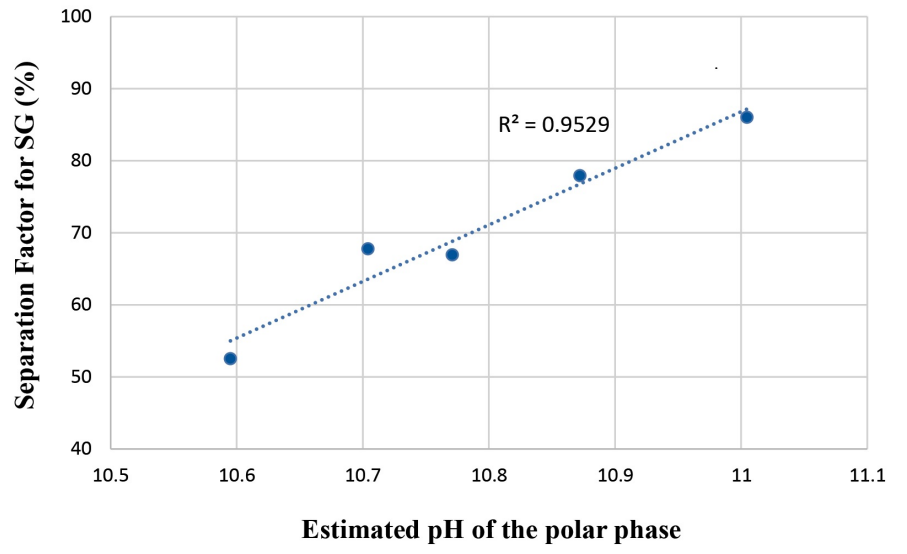

Fig.5. Separation factor for SG $v s$. estimated $\mathrm{pH}$ of the polar phase for FAME produced from 0.7 wt. \% cat. Runs.

FAME/methanol with the same total Hildebrand value should also exhibit similar solubility behaviour towards SG.

The Hildebrand solubility of the reacted ester phase was determined using methanol and catalyst phase partitioning data (Batista et al., 2015) and plotted as shown in Figure 6. Table 1 lists the Hildebrand solubility parameter values for pure methanol, acetone, and FAME. The presence of methanol in FAME increased the polar and hydrogen bonding components in the mixture, and compatibilized SG in the FAME phase.

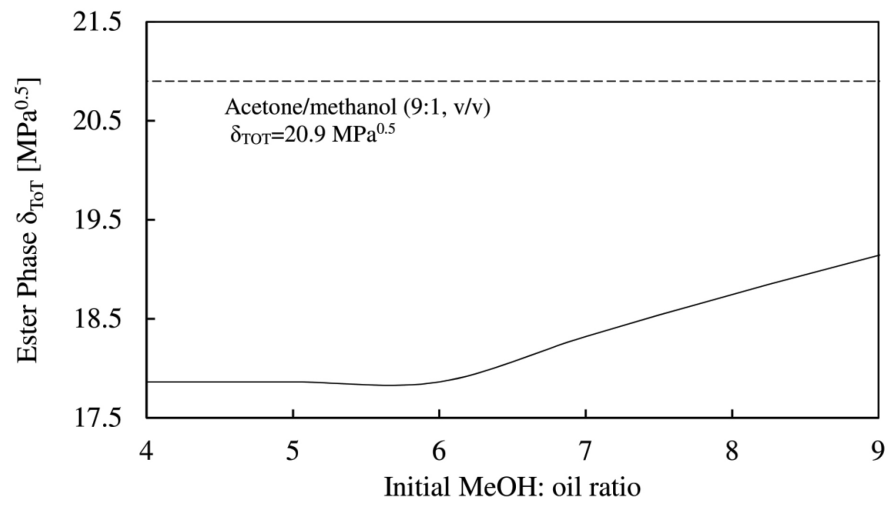

Fig.6. Estimated Hildebrand solubility value of final FAME phase vs. MeOH:Oil in initial reaction mixture.
Table 1.

Hildebrand solubility parameter values of methanol, acetone, and FAME (Batista et al. 2015).

\begin{tabular}{lcccc}
\hline & $\begin{array}{c}\boldsymbol{\delta}_{\mathbf{D}} \\
{\left[\mathbf{M P a}^{0.5}\right]}\end{array}$ & $\begin{array}{c}\boldsymbol{\delta}_{\mathbf{P}} \\
{\left[\mathbf{M P a}^{0.5}\right]}\end{array}$ & $\begin{array}{c}\boldsymbol{\delta}_{\mathbf{H}} \\
{\left[\mathbf{M P a}^{0.5}\right]}\end{array}$ & $\begin{array}{c}\boldsymbol{\delta}_{\text {Total }} \\
{\left[\mathbf{M P a}^{\mathbf{0} .5}\right]}\end{array}$ \\
\hline Methanol & 15.1 & 12.3 & 22.3 & 29.6 \\
Acetone & 15.5 & 10.4 & 7.01 & 19.94 \\
FAME & 15.03 & 3.69 & 8.92 & 17.86 \\
\hline
\end{tabular}

A reaction mixture having an initial MeOH:Oil ratio higher than 6:1 will have excess methanol present in the FAME phase, changing the solubility parameter value of the FAME phase. As the fraction of methanol present in the FAME phase increased, the mixture's solubility parameter increased towards that of acetone/methanol $(9: 1, \mathrm{v} / \mathrm{v})$ favoring the solubility of SG in FAME.

\subsection{FAME produced at $0.7 \mathrm{wt} . \%$ catalyst}

FAME produced with 0.7 wt.\% catalyst were close to ASTM and EN standards. Results from this level of catalyst were selected to determine the effect of ultrafiltration on the minor components found in the permeate from the membrane separation. These results are listed in Table 2. The levels of MG, DG, and TG in the FAME produced using $0.7 \mathrm{wt} . \%$ catalyst and MeOH:Oil ratios of 7:1 and 9:1 met EN14214 standards. This was achieved using a single reaction step and ultrafiltration was able to reduce the SG levels to $68 \%$ and $52 \%$, respectively. The lowest level of SG, i.e., $3.4 \mathrm{ppm}$, was found in the permeate obtained for FAME produced using a $\mathrm{MeOH}$ :Oil ratio of 4:1. This corresponded to a separation factor of $86 \%$.

Table 2.

Summary of results for FAME produced using $0.7 \mathrm{wt} . \%$ catalyst.

\begin{tabular}{|c|c|c|c|c|c|c|c|}
\hline \multirow{2}{*}{ MeOH:Oil } & \multicolumn{4}{|c|}{$\begin{array}{l}\text { Analysis of permeate } \\
\text { (ASTM 6584) }\end{array}$} & \multicolumn{3}{|c|}{$\begin{array}{c}\text { SG analysis method } \\
\text { (Montpetit and Tremblay, 2016) }\end{array}$} \\
\hline & $\begin{array}{c}\text { MG } \\
\text { [wt. \%] }\end{array}$ & $\begin{array}{c}\text { DG } \\
\text { [wt. \%] }\end{array}$ & $\begin{array}{c}\text { TG } \\
\text { [wt. \%] }\end{array}$ & $\begin{array}{c}\text { Conversion } \\
{[\%]}\end{array}$ & $\begin{array}{c}\text { [SG] } \\
\text { Retentate } \\
(\mathbf{p p m})\end{array}$ & $\begin{array}{c}\text { [SG] } \\
\text { Permeate } \\
(\text { ppm) }\end{array}$ & $\begin{array}{l}\text { SF } \\
(\%)\end{array}$ \\
\hline 4 & 0.391 & 0.804 & 3.65 & 95.2 & 24 & 3.4 & 86.0 \\
\hline 5 & 0.317 & 0.454 & 1.796 & 97.5 & 34 & 7.5 & 77.9 \\
\hline 6 & 0.309 & 0.286 & 0.859 & 98.5 & 32 & 10.6 & 67.0 \\
\hline 7 & 0.302 & 0.119 & 0.018 & 99.6 & 17 & 5.5 & 67.8 \\
\hline 9 & 0.329 & 0.124 & 0.033 & 99.5 & 24 & 11.4 & 52.6 \\
\hline
\end{tabular}

Table 3.

Summary table of the catalyst and MeOH:Oil levels affecting SG separation and the resulting solubility of SG in FAME.

\begin{tabular}{|c|c|c|c|c|c|}
\hline Catalyst level & Methanol level & Experimental coordinates & Separation factor for SG $(\%)$ & TG [wt.\%] & Discussion \\
\hline+ & - & 0.7 wt. $\%$ cat, $4: 1$ & $86.0 \%$ & 3.6 & $\begin{array}{l}\text { High deprotonation of SG, low methanol in FAME. Limited SG } \\
\text { solubility in FAME. SG rejected from FAME phase leading to high } \\
\text { separation. }\end{array}$ \\
\hline- & - & 0.3 wt. $\%$ cat, $4: 1$ & $0 \%$ & 24 & $\begin{array}{l}\text { High TG, MG, DG levels solubilizes SG in FAME phase and transports } \\
\text { them through the membrane leading to low separation. }\end{array}$ \\
\hline+ & + & 0.7 wt. $\%$ cat, $9: 1$ & $52.6 \%$ & 0.032 & $\begin{array}{l}\text { Excess } \mathrm{MeOH} \text { increases solubility of SG in FAME. Lower TG, MG, DG } \\
\text { decreases solubility in FAME. Leads to intermediate solubility and } \\
\text { separation. }\end{array}$ \\
\hline- & + & 0.3 wt. $\%$ cat, $9: 1$ & $41.7 \%$ & 6 & $\begin{array}{l}\text { Higher methanol in FAME, lower catalyst } \Rightarrow \text { less deprotonation. } \\
\text { Intermediate TG. Net effect is intermediate SG solubility, higher } \\
\text { solubility (lower separation) than the }++ \text { case }\end{array}$ \\
\hline
\end{tabular}




\subsection{Summary of results}

A summary of the phenomena affecting SG separation and solubility in FAME at the extreme corners of the analytical space can be found in Table 3 .

\section{Conclusions}

SG is a problematic compound that restricts the use of biodiesel. The separation of SG from reacted FAME mixtures was studied in this work. The highest separation $(86 \%)$ was obtained at the highest levels of SG deprotonation. The separation was the lowest $(0 \%)$ when unreacted TG along with MG and DG solubilized SG in the reacted FAME mixture.

The use of ultrafiltration after the transesterification reaction and before phase separation or post-treatment was highly beneficial in separating SG from biodiesel. The lowest levels of SG, i.e., $3.4 \mathrm{ppm}$, in FAME were obtained at the higher catalyst concentrations and lower methanol:oil ratios. The use of ultrafiltration in biodiesel production can reduce the polishing and postprocessing requirements currently needed to remove insoluble precipitates from biodiesel.

\section{Acknowledgements}

The authors wish to acknowledge the support of the Natural Sciences and Engineering Research Council of Canada (NSERC) - Discovery Grants program.

\section{References}

[1] Aguirre, A., Peiru, S., Eberhardt, F., Vetcher, L., Cabrera, R., Menzella, H.G., 2014. Enzymatic hydrolysis of steryl glucosides, major contaminants of vegetable oil-derived biodiesel. Appl. Microbiol. Biotechnol. 98(9), 4033-4040.

[2] Batista, M.M., Guirardello, R., Krähenbühl, M.A., 2015. Determination of the hansen solubility parameters of vegetable oils, biodiesel, diesel, and biodiesel-diesel blends. J. Am. Oil Chem. Soc. 92(1), 95-109.

[3] Chemspider, Chemical-Structure. (accessed on 20 Feb 2017).

[4] Csernica, S.N., Hsu, J.T., 2012. The phase behaviour effects on the kinetics of transesterification reactions for biodiesel production. Ind. Eng. Chem. Res. 51(18), 6340-6349.

[5] Danzer, M.F., Ely, T.L., Kingery, S.A., McCalley, W.W. McDonald, W.M., Mostek, J., Schultes, M.L., 2015. Biodiesel cold filtration process. US Patent 9109170 B2.

[6] Gerpen, J.V., Shanks, B., Pruszko, R., Clements, D., Knothe, G., 2004. Biodiesel Production Technology. NREL/SR-510-36244, report.

[7] Gerpen, J.V., He, B.B., Duff, K., 2011. KLK755: measurement and control strategies for sterol glucosides to improve biodiesel quality. National Institute for Advanced Transportation Technology, University of Idaho.

[8] Lee, I., Pfalzgraf, L.M., Poppe, G.B., Powers, E., Haines, T., 2007. The role of sterol glycosides on filter plugging. Biodiesel Mag. 4, 105-112. (accessed on 2 Feb 2017).

[9] Montpetit, A., Tremblay, A.Y., 2016. A quantitative method of analysis for sterol glycosides in biodiesel and FAME using GC-FID. J. Am. Oil Chem. Soc. 93(4), 479-487. 